\title{
Colcha de retalhos e apropriação de histórias: um encontro do idoso consigo mesmo e com o outro
}

\author{
Recolección de patchwork y apropiación de historias: un encuentro de \\ ancianos con ellas mismas y con el otro.
}

\section{Patchwork collection and stories appropriation: a meeting of the elderly with itself and with the other}

\author{
Heloisa de Campos Honorato ${ }^{a}\left[\right.$ [) , Gabriela Pereira Vidal $^{\mathrm{b}}$ [-] e Amanda Castro \\ a Psicóloga (UNESC). Universidade do Extremo Sul Catarinense, UNESC, Criciúma/SC, Brasil. E-mail: heloisach@hotmail.com. \\ ${ }^{\mathrm{b}}$ Psicóloga (UNIBAVE), Pós graduanda em Psicodrama (Viver Psicologia Psicodrama). Centro Universitário Barriga Verde - UNI- \\ BAVE/ Viver Psicologia Psicodrama, Braço do Norte/SC, Brasil. E-mail: gabrielavidaal@gmail.com \\ ${ }^{\mathrm{c}}$ Doutora em Psicologia (UFSC), Professora de Psicologia (UNESC). Universidade Federal de Santa Catarina, Florianópolis/SC e \\ Universidade do Extremo Sul Catarinense, Florianópolis/SC, Brasil. E-mail: amandacastrops@gmail.com.
}

Resumo: O presente estudo teve como objetivo caracterizar a identidade social de idosas a partir do reconhecimento das singularidades e das complementariedades e resgate de histórias de vida. Após o período de observações e o levantamento das demandas, deu-se início as intervenções com o grupo de idosas do SCFVI que se configuraram em encontros semanais, envolvidos pela realização da técnica Colcha de Retalhos. Por meio do método de pesquisa-ação, os encontros foram sustentados por uma atuação nas demandas emergentes do grupo. As histórias compartilhadas que eram diferentes ou desconhecidas pelas demais integrantes do grupo, geravam curiosidade e interesse nas mesmas, enquanto que as histórias semelhantes ou que traziam vivências comuns entre elas, aproximavam o grupo que passava de uma atitude de narrar histórias de vida, para dialogar sobre as mesmas. Acredita-se ainda que ambos os processos influenciaram diretamente no vínculo do grupo e na identidade grupal das integrantes.

Palavras-chave: Idosos; Identidade; Envelhecimento; Velhice.

Resumen: El presente estudio tuvo como objetivo caracterizar la identidad social de las mujeres mayores basándose en el reconocimiento de singularidades y complementariedades y la recuperación de historias de vida. Después del período de observación y la encuesta de las demandas, se iniciaron intervenciones con el grupo de mujeres mayores de SCFVI que se

Como citar o artigo: HONORATO, Heloisa de Campos; VIDAL, Gabriela Pereira; CASTRO, Amanda. Colcha de retalhos e apropriação de histórias: um encontro do idoso consigo mesmo e com o outro. Revista de Ciências Humanas, Florianópolis, v. 53, 2019 DOI: 10.5007/2178-4582.2019.e58332 você pode compartilhar, adaptar, para qualquer fim, desde que atribua a autoria da obra, forneça um link para a licença, e indicar se foram feitas alterações. 
configuraron en reuniones semanales, involucradas mediante la realización de la técnica Patchwork. A través del método de investigación-acción, las reuniones fueron apoyadas por un desempeño en las demandas emergentes del grupo. Las historias compartidas que eran diferentes o desconocidas para los otros miembros del grupo generaron curiosidad e interés en ellas, mientras que historias similares o que trajeron experiencias comunes entre ellos, acercaron al grupo desde una actitud de narrar historias de vida hasta el diálogo a cerca de ellas mismas. También se cree que ambos procesos influyeron directamente en el vínculo del grupo y en la identidad grupal de los miembros.

Palabras clave: Ancianos; Identidad; Envejecimiento; Vejez.

\begin{abstract}
The present study aimed to characterize the social identity of elderly women based on the recognition of singularities and complementarities and the recovery of life stories. After the observation period and the survey of the demands, interventions were initiated with the group of elderly women from SCFVI that were configured in weekly meetings, involved by performing the Patchwork technique. Through the action-research method, the meetings were supported by a performance in the emerging demands of the group. Shared stories that were different or unknown to the other members of the group generated curiosity and interest in them, while similar stories or that brought common experiences between them, brought the group close together from an attitude of narrating life stories, to dialogue about them. It is also believed that both processes directly influenced the group's bond and the group identity of the members.
\end{abstract}

Keywords: Elderly; Identity; Aging; Old age.

\title{
1 INTRODUÇÃO
}

A construção da identidade pessoal parte desde os primórdios da vida infantil, quando por meio das relações com o outro, geralmente a mãe, a criança começa a desenvolver um autoconceito (que precede a identidade propriamente dita). Pouco a pouco reconhece sua imagem como sua e passa a fazer algumas descrições sobre si, geralmente apoiadas nas afirmações relativas à sua pessoa feitas pelos adultos com quem tem contato (PAPALIA; FELDMAN, 2013, p. 227-228).

Por ser a identidade um processo contínuo, incompleto e mutável, se desenvolve e resignifica durante toda a vida de um indivíduo. Mas na adolescência, em especial, esta se constitui como um importante processo com um enfoque maior por parte do indivíduo, quando, por meio de um autoconceito mais definido e uma visão de futuro baseada em valores, crenças e metas, o adolescente constrói sua identidade de fato (FERREIRA; FARIAS; SILVARES, 2003, p. 107). A partir disso, vários momentos, situações, ocupações e pessoas poderão influenciar e culminar em mudanças nesta identidade, acontecimento típico de um processo contínuo e mutável.

Estar idoso, representa um momento de transição marcado por mudanças significativas na vida do indivíduo, tanto físicas quanto sociais, o processo de reorganização da identidade enfrenta conflitos relacionados ao estigma social e a representações negativas referentes a esta fase da vida, e, como afirma Santos (1994, p. 126) "Se a identidade pessoal se constrói no jogo das relações sociais, uma representação social negativa do grupo ao qual o sujeito pertence poderá fazer eclodir uma representação negativa de si mesmo.". Entende-se, portanto, que uma visão negativa difundida pela sociedade acerca do idoso, corroborada à estudos que também apontam o processo de envelhecimento como algo negativo, pode influenciar negativamente na identidade da pessoa idosa.

No contexto social, a visão da velhice como uma fase da vida marcada por limitações, tem comprometido o reconhecimento do idoso e seus papéis sociais, assim, influenciando diretamente na formação da sua identidade. Diante disso, quando o idoso precisa reafirmar a sua identidade pessoal, e enfrenta uma estigmatização social onde deveria encontrar amparo para a formação da sua identidade, este poderá buscar esta afirmação através das lembranças de sua história de vida.

De acordo com Valença e Reis (2015) a narrativa das memórias de um idoso, lhe possibilitam, além de um sentimento de valorização por transmitir conhecimento para as outras gerações, (re)cons- 
truir sua própria identidade. Tem-se ainda que o ato de "Contar histórias, conversar, narrar fatos são maneiras de a memória vir à tona, oferecendo a oportunidade para a pessoa produzir sentidos, identificar-se, posicionar-se e relacionar-se dentro do seu ambiente social" (VALENÇA; REIS, 2015, p.274).

E por estar inserido em um contexto social, ao narrar suas histórias de vida, a priori particulares, o idoso dá o seu depoimento sobre práticas sociais, pois, embora as experiências sejam subjetivas, raramente são individuais. A maioria das histórias ocorrem dentro de um coletivo, seja ele um grupo específico ou uma sociedade inteira, e desta forma, tais memórias permitem, além da reafirmação da identidade pessoal, a manutenção de uma identidade grupal na qual o indivíduo influencia e é influenciado a nível de identidade social (VALENÇA; REIS, 2015, 267).

O sentimento de identidade é o sentimento de ser enquanto pessoa diferente dos outros e enquanto ator social, com o conjunto de papéis e de funções que o tornam semelhante aos outros. Ter uma identidade é, então, estar só, no sentido de unidade, e estar com o outro, na medida em que se compartilham os valores e as representações do grupo social e da cultura a que se pertence (SANTOS, 1990, p. 16)

Ao considerar-se a identidade e os grupos sociais neste processo de identificação pessoal e social, tem-se ainda, mais uma forma de reafirmação da identidade do idoso, por meio dos seus iguais, pois como afirma Moreira $(2012$, p. 95) " [...] há sempre outras pessoas na mesma condição, que mostram que já passaram pelos mesmos problemas, o que facilita, de certa forma, a reorganização dos conceitos preexistentes acerca da velhice.".

O que determina esses iguais são características comuns a vários indivíduos e suas identidades pessoais, como etnia, profissão, família e idade, essas semelhanças de condições sociais possibilitam a identificação da sua identidade social, a partir da qual o indivíduo de insere em um grupo e adquire sua respectiva identidade grupal.

A identidade social de um indivíduo se caracteriza pelo conjunto de suas vinculações em um sistema social: vinculado a uma classe sexual ${ }^{1}$, a uma classe de idade, a uma classe social, a uma nação, etc. A identidade permite que o indivíduo se localize em um sistema social e seja localizado socialmente. (BERLATTO, 2009, p.142).

Da mesma forma, o idoso, compartilha desta identidade social quando se identifica com "[...] um conjunto de indivíduos semelhantes a ele em idade, que atravessaram acontecimentos históricos também semelhantes e partilham experiências, o que fornece a eles determinada visão de mundo." (MOREIRA, 2012, p. 94), ou seja, quando ele se identifica como pertencente a uma geração.

A concepção relacional e situacional de identidade percebe os membros de um grupo como os próprios atores que se atribuem uma significação a sua vinculação, em função da situação relacional em que se encontram, visto que é no interior das trocas sociais que a identidade se constrói e se reconstrói constantemente. (BERLATTO, 2009, p. 143)

E a medida que a identidade garante ao indivíduo um sentimento de existência e reconhecimento de si pelo outro ou ainda pelo grupo no qual se insere, quando o idoso se enquadra em uma geração, em um grupo social, acaba se tornando "[...] consciente do seu espaço na esfera social, a pessoa idosa sintetiza uma nova imagem de si mesmo, se conceituando como alguém ativo, útil e competente para contribuir com o cenário social em que se encontra inserido." (MARTINS; SANTOS; CAROLINO, 2015, p. 6).

1 Utilizado o termo "classe sexual" em respeito a nomenclatura utilizada pelo autor, mas atualmente as identidades de gênero não se configuram como um sistema classificatório. 
As atividades socioculturais direcionadas à pessoa na idosa, possibilitam estes encontros entre iguais que se afirmam nas semelhanças e singularidades, se acolhem e possibilitam, a partir de um sentimento de pertença e familiaridade, as expressões mais íntimas em buscas dos desejos outrora reprimidos. Este processo a qual se refere este tópico, não se resume, portanto, como uma simples identificação pessoal e/ou social, mas também, uma libertação de padrões sociais reducionistas e limitadores, baseados em estereótipos.

A partir da análise das evidências mais recentes acerca do processo de envelhecimento, a Organização Mundial da Saúde (OMS) desenvolveu o Relatório Mundial de Desenvolvimento e Saúde onde tem-se que "[...] muitas percepções e suposições comuns sobre as pessoas mais velhas são baseadas em estereótipos ultrapassados." (OMS, 2015, p. 3), já que, "Como mostra a evidência, a perda das habilidades comumente associada ao envelhecimento na verdade está apenas vagamente relacionada com a idade cronológica das pessoas." (OMS, 2015, p.3).

Portanto, para fins de conceituação, adotar-se-á neste trabalho uma linha de definição baseada na idade cronológica do ser humano, mas considerando que, este limite cronológico adotado, não responde diretamente às alterações decorrentes do envelhecimento. Nesse sentido, este artigo tem por objetivo caracterizar a identidade social de idosas a partir do reconhecimento das singularidades e das complementariedades e resgate de histórias de vida.

\section{MÉTODO}

As demandas para intervenção foram levantadas a partir de um período destinado a observações do espaço e segmentos da instituição. Com tal objetivo, optou-se pelo uso da observação participante, enquanto método de investigação qualitativo, na qual poderá se ter uma visão o mais realista possível da realidade a ser observada. A partir disso, obtendo-se informações fiéis acerca das demandas do grupo, foi possível estruturar as intervenções necessárias, através do método de pesquisa ação para a realização da intervenção continuada no grupo. Através da pesquisa ação é possível que as ações no campo sejam praticadas concomitantemente à uma avaliação das mesmas, permitindo que se avalie a sua eficácia e a necessidade de mudanças e de aprimoramentos (GIL, 2008).

Durante os meses de março e junho de 2018, portanto 04 meses, foram elaboradas observações e intervenções em grupo. Os primeiros 2 dias de observação foram dedicados a conhecer o local, o funcionamento e segmentos da instituição, assim sendo, a psicóloga e supervisora local, acompanhou a pesquisadora no processo, apresentando os serviços e profissionais do local e tirando as dúvidas que surgiam a mesma. A partir disso, constatou-se que o CRAS de Timbé do Sul oferece o Serviço de Convivência e Fortalecimento de Vínculos para crianças e adolescentes de 6 a 15 anos de idade e idosos acima de 60 anos, Serviço de Proteção e Atendimento Integral à Família e o serviço de Proteção Social Básica no Domicílio para Pessoas com Deficiência e Idosas. Para as pessoas idosas o serviço é oferecido uma vez por semana, nas segundas-feiras, e tem como atividade de oficina o artesanato.

Após uma apreciação geral do local de intervenção e seu respectivo funcionamento e de esclarecimento feitos pela psicóloga, constatou-se que, em relação aos demais grupos de usuários do local, o grupo de idosas do SCFV encontrava-se de certa forma desassistido dos serviços que vão além da oficina de artesanato realizada uma vez por semana. O que motivou a mesma a realizar um processo de observação participante neste grupo, culminando então, na participação em dois encontros do grupo em um período de duas semanas. Nestes encontros a estagiária procurou, em primeiro lugar, conhecer o grupo como um todo e se apropriar de sua realidade.

Favorecendo-se dos benefícios de uma observação participante, a estagiária pôde vivenciar de forma ativa o contexto em questão, realizando um processo de investigação mais realista sobre o grupo, o qual se mostrou receptivo a presença da estagiária. Este processo, permitiu constatar-se que se trata de um grupo de idosas muito ativas, que gostam de frequentar o serviço, em parte pela ativi- 
dade realizada, mas principalmente pelo simples ato do encontro entre elas. Em relação às atividades, através de algumas falas, percebeu-se que dos trabalhos produzidos por elas, no grupo ou em casa, geralmente os mais bonitos nunca ficam para si, ou vendem ou presenteiam alguém.

Pode-se perceber ainda que os encontros são permeados por conversas diversas que servem de descontração durante a realização da atividade proposta, os assuntos versam de família, festas, lembranças, piadas, as vezes envolvendo o grupo todo, as vezes se fragmentando em pequenos grupos contidos no grupo maior.

Motivada pelo contexto observado e instigada a oferecer as idosas a oportunidade de realizarem um trabalho voltado para elas mesmas, a estagiária propôs ao grupo, a realização de uma colcha de retalhos. Esta atividade, além de estar em consonância com a realidade do grupo, pelo fato de lidar com a prática de corte e costura, abarca a característica do mesmo de trabalharem envolvidas em uma roda de conversa, na medida em que propõe que as idosas contem suas próprias histórias de vida enquanto costuram retalhos para construir uma colcha.

Diante do aceite das idosas para a realização da atividade proposta, deu-se início aos encontros semanais, com temas adequados as demandas do grupo, que emergiam durante as falas das participantes. Após o período de observações e o levantamento das demandas, deu-se início as intervenções com o grupo de idosas do SCFVI que se configuraram em encontros semanais, envolvidos pela realização da técnica Colcha de Retalhos. Por meio do método de pesquisa-ação, os encontros foram sustentados por uma atuação nas demandas emergentes do grupo, portanto, os temas a serem abordados eram definidos previamente junto as idosas mediante as necessidades das mesmas.

\section{RESULTADOS E DISCUSSÃO}

Buscou-se com a construção da história de vida das participantes propiciar através da técnica "Colcha de Retalhos" o fortalecimento da identidade pessoal e favorecer a formação da identidade social das idosas, além de fomentar a abertura de espaços para acolhimento de expressão de sentimentos. Tendo por objetivo geral, fortalecer a coesão do grupo de idosas a partir do reconhecimento das singularidades e das complementariedades presentes no grupo. A confecção desta colcha e construção das histórias de vida ali contidas, teve início com a apresentação das autoras destas histórias.

Inicialmente, as atividades relatadas foram precedidas por um período destinado a observação do público e dos segmentos da instituição, com o objetivo de identificar possíveis demandas que subsidiariam e sustentariam as atividades a serem realizadas. Após uma apreciação geral do local e seu respectivo funcionamento, concentrou-se as atividades de observação-participante no grupo de idosas do SCFV do CRAS - Casa da Família de Timbé do Sul.

A partir deste processo, favorecendo-se dos benefícios de uma observação participante, pode-se traçar um perfil do grupo e desenvolver uma proposta de atuação com o mesmo. Ao se apropriar da dinâmica do grupo de idosas que frequentam o serviço, constatou-se que a atividade realizada por elas (bordado) e a forma como se organizam durante o encontro, permitem as mesmas realizarem essa atividade de forma descontraída, envolvidas por uma roda de conversa.

Diante disso, acreditou-se que a técnica Colcha de Retalhos era apropriada para o grupo, uma vez que unia duas características essenciais do mesmo, o trabalho manual com costura e a roda de conversa. Ainda, esta prática deu liberdade e flexibilidade à facilitadora do grupo de atuar de acordo com as necessidades do mesmo, por meio do método de pesquisa-ação, os encontros eram sustentados por uma atuação nas demandas emergentes do grupo.

Buscou-se através da técnica "Colcha de Retalhos" e respectiva construção da história de vida das participantes propiciar o fortalecimento da identidade pessoal e favorecer a formação da identidade social das idosas, além de fomentar a abertura de espaços para acolhimento de expressão de sentimentos. Tendo-se ainda como objetivo geral, fortalecer a coesão do grupo de idosas a partir do 
reconhecimento das singularidades e das complementariedades presentes no grupo e, consequentemente, compartilhadas com o mesmo, enquanto eram contadas as histórias de vida.

Ao julgar a importância da noção de identidade para a formação pessoal e social do sujeito e ainda, a crise de identidade típica do idoso, considerou-se este um tema de relevância a ser trabalhado com um grupo de idosas que busca manter seu vínculo social se inserindo em grupos como o do SCFVI e o de dança dos idosos do município, atividades distintas que parecem gerar um sentimento de pertença a estas mulheres.

Sendo a identidade, continuamente influenciada pela sociedade, acredita-se que o melhor lugar para a reafirmação desta identidade do idoso seria em um grupo de pessoas na mesma condição, retomando aqui os pensamentos de Moreira de que "há sempre outras pessoas na mesma condição, que mostram que já passaram pelos mesmos problemas, o que facilita, de certa forma, a reorganização dos conceitos preexistentes acerca da velhice" (MOREIRA, 2012, p. 95).

Buscou-se assim construir as histórias de vida das participantes baseadas em pessoas e momentos que surgiam nos encontros e, portanto, indicavam assumir um papel relevante na formação da identidade de cada idosa. O processo foi iniciado a partir da visão da própria idosa acerca da sua identidade pessoal, momento em que, percebeu-se uma forte tendência entre as idosas de buscar uma definição para si a partir dos papéis sociais que desempenham na sociedade, principalmente os papéis parentais. Durante este processo houveram relatos de lembranças concretas "Escolhi este tecido porque me lembrou um vestido que eu tinha, e por estar curto meu pai não me deixou ir no culto", "Escolhi este tecido porque lembrava o terninho que meu pai usava", e algumas associações um pouco mais abstratas "Escolhi este tecido porque ele é alegre e eu sou muito alegre.".

De fato, os papéis sociais se constituem como definidores de um indivíduo, porém, em prol da sociedade, mais se configurando como uma identidade social estabelecida em prol da sociedade, do que uma apropriação do sujeito sobre quem se é. E neste panorama social, a identidade pessoal e os papéis sociais se confundem, a ponto de haver um predomínio destes últimos sobre a subjetividade do indivíduo, como afirma Martins (2010, p. 44) "se perder em meio aos papéis atribuídos ou adquiridos pode significar deixar de existir, existir enclausurado, [...]”, assim, é importante que o indivíduo se perceba com outras características, como algo além de seus papéis sociais.

Para se estabelecer um cenário social organizado e regularmente estruturado, entende-se ser necessário esta atribuição dos papéis sociais, uma vez que eles se constituem como uma referência comportamental para o convívio em sociedade. Mas na medida que esta consciência coletiva anula a consciência individual do sujeito, de modo que, este não consiga fazer uma distinção entre quem se é e os papéis desempenhados,

[...] a individualidade permanece submersa nessas obrigações e com o passar do tempo seja através da socialização primária ou secundária, o comportamento interiorizado se torna tão comum e mecânico que a individualidade se esquece na inconsciência dessas formas classificatórias a serviço de seus propósitos. (MARTINS, 2010, p. 45-46)

Portanto, é compreensível o motivo pelo qual ao buscarem uma definição para si, as idosas recorram aos diversos papéis atribuídos a elas na sua história de vida por este modelo social, estes papéis sociais já estão tão enraizados que elas os assumem como meras personagens sem questionar o lugar de sua subjetividade. Além de que "distinguir os papéis sociais no cenário social e se distinguir neste mesmo cenário implica em reflexão e não conformação ao automatismo" (MARTINS, 2010, p. 50), processo que embora seja de grande relevância, é muito complexo de ser realizado.

Se fortalece assim o conjunto de motivações que justificam a necessidade de se trabalhar a identidade com idosos, de forma que a pessoa idosa se coloque na sociedade como uma subjetividade, e não simplesmente um conjunto atribuído ou conquistado de papéis sociais efêmeros. Buscou-se, portanto, aprofundar a discussão dos papéis sociais buscando em alguns deles, considerados relevantes pela emergência nas discus- 
sões do grupo, os motivos de serem tão definidores da personalidade das idosas em questão. Um processo de diálogo que busca conscientizar as autoras destas histórias de vida acerca da sua identidade pessoal.

Por consequência desta tendência classificatória de auto conceituação, e a prevalência de papéis sociais relacionados ao contexto familiar das idosas neste processo, este se tornou o primeiro tema a ser aprofundado no grupo, a influência da família na formação da identidade pessoal das idosas. Acredita-se que quando as idosas colocam suas famílias em uma posição de suporte de vida, estão, mesmo que talvez não saibam, definindo de fato a influência da família no processo de identificação do sujeito.

Durante este momento de intervenção com o tema, surgiu uma família que é base, que dá suporte e sustentação para a construção de um ser, nas palavras delas, uma família que é "tudo". A maioria dos relatos em relação a família eram de conotação positiva, alguns consistiram ainda em contar histórias de acontecimentos passados ou recentes/presentes envolvendo estas pessoas, uma das mulheres muito empolgada relatou que trouxe aquele pedaço de tecido escolhido pois a muitos anos sua mãe havia lhe pedido para costurar algo com ele, e não tendo feito isso, após a morte da mãe este tecido estava na sua casa sem ela saber o que fazer com ele, mas naquele momento ela o colocaria na colcha como parte da sua história.

A família, como primeira instância socializadora da criança, tem uma influência direta na formação da identidade deste novo integrante. Concerne à família ser um grupo de referência para o indivíduo, o núcleo social primário onde este irá adquirir suporte mediante a sua dependência física e psíquica, característica dos primeiros anos de vida, e adquirir também, neste contexto familiar, o suporte para a formação da sua identidade.

Inserida no meio familiar, a criança aprende a significar suas primeiras ações, internalizando, cotidianamente, signos e símbolos que servem de mediadores fundamentais para a organização de seu pensamento, atuando também no desenvolvimento de suas funções psicológicas superiores. À medida que a criança se desenvolve e acumula experiências por meio da relação com adultos e outras crianças mais velhas ou mais experientes, ela passa por um processo de individuação, isto é, de afirmação enquanto sujeito único. (BARBOSA; REIS, 2009, p. 3)

Considerando a definição de família como um núcleo social, acredita-se ser este um contexto primordial no desenvolvimento da identidade do sujeito. Além deste papel fundamental no processo de formação da identidade, a família é um meio social que atribui ao sujeito muitos papéis, foi na família e pela família que estas idosas desenvolveram e desempenham seus papéis de mães, filhas, avós, tias, esposas etc. Portanto, o núcleo familiar ao qual estas idosas se referem como "base" de suas vidas, estão desde sua concepção até hoje influenciando na sua identidade, pessoal e social.

Além disso, como destaca Paúl (2005) em seu estudo sobre as possíveis relações entre o apoio social e aspectos específicos do processo de envelhecimento, as redes de suporte social, como a família, podem estar associadas a maior qualidade de vida dos idosos. Sendo que este define estas redes de suporte social associando-as a um sentimento de pertença a um grupo ou a existência de laços familiares, ou ainda por suas funções de apoio emocional, informativo, tangível e de pertença. Nas suas concepções teóricas, o autor destaca ainda que o suporte social vindo das redes de amigos é potencialmente mais positivos do que o suporte familiar, isto pelo fato de as amizades serem uma escolha voluntária do indivíduo, ao contrário do aspecto involuntário das redes familiares (PAÚL, 2005).

E como "A identidade é um processo, um constante vir-a-ser do sujeito." (BARBOSA; REIS, 2009 , p. 4), quando este sujeito cria laços de amizade na sua história de vida, estas relações, além de assumirem a posição de suporte social descrita por Paúl (2005), também influenciam o sujeito a nível de formação de identidade. Assim, quando as idosas se referem às suas amizades em um processo de construção de histórias de vida, estão expressando a importância destas relações para si. Também tendo o tema amizade se destacado durante as falas das idosas ao buscarem algo que as definisse, este foi aprofundado no grupo em momento oportuno. 
Assim como a família, as amizades também assumem um papel norteador na formação da identidade do sujeito. Esta tem um papel fundamental no período da adolescência, momento em que, de acordo com a teoria psicossocial de Erikson, ocorre o ápice no processo de construção da identidade. O processo de identificação, que já ocorria na infância na relação com os pais, agora exige novos modelos identificatórios, novas referências, representados nas figuras de amizade, que assim como o relacionamento familiar, vai permitir ao mesmo descobrir a si próprio por meio da oposição ou identificação com aqueles que lhe circundam.

Ao se referirem as suas relações de amizade, as idosas deixavam explícito a função de companhia que estas pessoas exercem em suas vidas, e indicavam que as amigas lhes acompanhavam nas suas atividades quando muitas vezes não podiam contar com a presença de um familiar ou mesmo cônjuge. Isto vai ao encontro dos dados expostos por Meira et al. (2015) em pesquisa realizada com idosos em estado de corresidência, "[...] um arranjo social de coabitação no qual duas ou mais pessoas, independentemente da geração, gênero ou nível de consanguinidade, compartilham o mesmo espaço físico." (MEIRA et al., 2015, 202). Nesta pesquisa, as autoras constataram que para muitos idosos, o benefício da corresidência está relacionado à companhia e ao suporte emocional, além do suporte financeiro e de cuidados físicos, tanto por parte dos pais como dos filhos. (MEIRA et al., 2015)

Da forma como se configuram as corresidências é possível que o idoso estabeleça através delas laços de amizade, e que estas interrelações assumam a posição destacada por Cuba quando afirma: "O vínculo de amizade assemelha-se aos vínculos familiares, por serem fontes de suporte, suprindo necessidades de interdependência e manutenção dos vínculos significativos na família" (2006, p. 58), levando em conta, que a corresidência pode ser uma estratégia familiar frente as dificuldades de manter um vínculo familiar ativo e capaz de suprir as necessidades do idoso, àqueles que convivem em estado de corresidência assumem uma posição de "família possível", intensificando ainda mais o sentimento de companhia gerado pela amizade.

Quanto a influência da amizade na identidade do sujeito, tem-se que a dialética entre oposição e identificação inerente ao processo de apropriação da identidade vai se estender por muitos momentos e crises ao longo da vida do indivíduo, surgindo quando este passar por ressignificações da sua identidade, inclusive enquanto idoso, onde as relações com seus iguais também podem culminar em uma ressignificação ou afirmação da sua identidade.

Ainda baseando-se no objetivo de fortalecer a identidade pessoal das idosas a partir do resgate de histórias de vida, percebeu-se que, não só as pessoas que estavam presentes na sua vida estabeleciam influência no processo de identificação das mesmas, mas aquelas que já haviam falecido eram frequentemente lembradas pelo grupo quando compartilhavam suas histórias de vida. Portanto, diante de situações no grupo em que esta perda parecia não ter sido bem elaborada pela pessoa que ficou, considerou-se necessário abordar o tema, para que estas tivessem a oportunidade de expressarem seus sentimentos e tê-los acolhidos pelo contexto grupal.

O fato de algumas idosas evitarem situações que lhes remetem diretamente a perda pode ser justificada por estas situações fazerem referência a sua própria condição etária que é associada a finitude ou ainda por conta de uma tendência da sociedade atual em reprimir e repreender a expressão de sentimentos de dor, como ressaltam Oliveira e Lopes (2008)

A morte, neste modelo social, é algo relegado a um segundo plano, a não ser discutido, como se isso pudesse evitá-la. É aquela interdita, que deve ser escondida, institucionalizada, medicalizada, sem grandes demonstrações de dor pelos enlutados, não mais portadora de ritos. (p. 2017)

Além disso, sendo essas pessoas, falecidos familiares ou amigos, a influência e importâncias destes na história de vida e processo identificatório das idosas não pode ser contestada, dado os resultados das discussões referentes a esses grupos sociais e a própria consideração das idosas sobre tal influência. 
$\mathrm{Na}$ intervenção com esse tema, uma das idosas se prontificou a iniciar a costura na colcha a partir da sua fala, a mesma relatou que desde o início dos encontros com a confecção da colcha, ela se emocionou, mas nunca deixou isso transparecer para o grupo, porém, diante deste tema foi inevitável demonstrar suas emoções, pois falar de perda lhe lembrava sua mãe que já não estava mais com ela, e que devido a pobreza em que viviam costurou muitas colchas de retalhos em sua vida, o que fazia estes encontros serem muito emocionantes para a mesma.

Todo este encontro foi permeado por emoções e falas de saudade, algumas se expressaram pela fala, outras por lágrimas, mas todas demonstraram já ter perdido alguém importante, alguém que fez parte da sua vida muito ou pouco tempo, mas que deixou fortes lembranças e, com certeza, muita influência na constituição da identidade das pessoas com quem conviveu. Uma idosa em especial não entrou em detalhes sobre suas perdas, mas ressaltou sua opinião sobre a importância da espiritualidade em suas vidas.

Considerando as crises no processo identificatório inerentes ao momento geracional do idoso, este tema foi abordado para identificar no grupo de idosas o nível de satisfação quanto a fase da vida em que elas se encontram e propiciar a partir disso, o fortalecimento da identidade social das mesmas. Percebeu-se que, de modo geral, as idosas se sentem bem na fase da vida em que se encontram, onde muitas se referiram à liberdade como um aspecto positivo fundamental.

Partindo do pressuposto de que esta liberdade referida pelas idosas estava associada a possibilidade de irem e virem quando e como quisessem e, principalmente participarem de atividades da comunidade quando sentissem vontade, estavam na verdade, além de evidenciar a contraposição a uma infância e juventude repressora associada aos valores morais, expressando sua condição de autonomia na fase da vida em que se encontram. Na proposta de um envelhecimento ativo, a autonomia é um dos fatores a serem considerados.

Além disso, vale ressaltar que a participação e convivência em grupos de idosos tem uma influência positiva na vivência de um envelhecimento com mais qualidade de vida. Assim, a inclusão de idosos em grupos de suporte social possibilita uma mudança na concepção de velhice enquanto limitação e impotência, tendo em vista que nesses grupos pode haver idosos ativos, autônomos, que se relacionam em diversos grupos etários. (MIRANDA; BANHATO, 2008, p. 73)

E assim como no processo exercido a partir desse projeto, continuamente dentro de um grupo que aproxima indivíduos, principalmente indivíduos da mesma faixa etária, se propicia o processo identificatório ou de ressignificação da identidade no envelhecimento. Acredita-se que a atividade realizada veio fortalecer e direcionar este processo pois como afirmam Valença; Reis (2015) a narração de memórias pelas pessoas idosas, propicia as mesmas a (re)construção de sua própria identidade.

A construção das histórias de vida das integrantes do grupo por meio da Colcha de Retalhos propiciou em muitos momentos uma identificação de cada participante com o grupo, e na medida que há uma identificação pode-se falar também em formação de identidade social. Nos encontros, percebeu-se situações em que as idosas se identificavam com as histórias umas das outras, se percebiam tendo vivenciado momentos e sentimentos muito semelhantes ao longo de sua vida, e isso lhes causava uma nostalgia em comum, que em um processo continuo e gradativo intensificou o vínculo do grupo. Obteve-se também falas relacionadas ao envelhecimento como uma fase da vida em que podem fazer muitas coisas que tinham vontade, mas não podiam fazer antes, e que com certeza é a melhor fase da vida. $\mathrm{O}$ tema em questão gerou falas positivas das idosas, como mulheres contentes e satisfeitas com a vida que levavam.

A persistente afirmação das idosas no encontro sobre o envelhecimento acerca da satisfação em realizar coisas que almejavam antes porém não podiam fazer, sugeriu a abordagem do tema sonhos e objetivos de vida no grupo, buscando delinear o quanto essas idosas estavam se permitindo atuar de forma ativa na sua vida em busca de seus ideais.

Durante a discussão dos sonhos atuais, a partir da observação de que os relatos de sonhos no presente eram mais escassos, a estagiária e as idosas juntas construíram uma discussão no grupo de que a sociedade as leva a acreditar que na idade atual delas não é mais possível sonhar ou realizar 
sonhos, e que isto já está tão enraizado socialmente, que elas de fato acreditam que não podem ou não devem sonhar. Esta situação ficou explicita na fala de uma idosa que antes mesmo de relatar seu sonho, destacou que acreditava não ser possível realizá-lo, a estagiária e outras integrantes do grupo indagaram o porquê desta afirmação, momento em que se identificou uma crença de impossibilidade baseada nas objeções sociais.

A estagiária levou o grupo a refletir sobre a situação, questionando se esta impossibilidade é real, se elas realmente não conseguem, não devem mais realizar seus sonhos. Tendo o grupo afirmado que nada lhes impedia de traçar objetivos em suas vidas, a estagiária lhes incentivou a manter este hábito que na infância e vida adulta, é o motivador para muitas realizações pessoais. Por fim, abriu-se espaço para que as idosas se presenteassem com seus fuxicos.

Percebeu-se durante a fala das idosas que muitos sonhos que tiveram durante sua vida, elas conseguiram realizar ou ainda estão realizando, mas que nesta questão, suas atitudes se limitam a conquistar sonhos e objetivos já pré determinados em outros momentos de suas vidas, muitas não se permitem traçar novos objetivos ou metas no momento presente.

A discussão sobre este tema com o grupo de idosas e principalmente sobre esta situação aludiu a uma discussão feita ainda na conceituação teórica deste projeto, quando se afirmava que a sociedade atual reprimia e oprimia as pessoas idosas. Silva e Marinho $(2008,233)$ vão defender que conforme a pessoa se perceba (adequada ou inadequada) e perceba os demais, "especifica o modo como ela se relaciona com os outros: com direitos ou não, relaxada ou tensa, com ou sem comportamentos assertivos ou habilidades sociais".

Trazendo para a discussão em questão, percebe-se que as idosas deste grupo estão se colocando na sociedade como aquelas que não podem e não devem sonhar, mas não porque a idade lhes impede de idealizar, traçar objetivos ou mesmo conquistá-los, e sim porque a sociedade lhes fez acreditar que elas não devem, que elas não conseguiriam. Fazendo uma alusão ao encontro no qual prevaleceram falas sobre liberdade, percebeu-se que, embora as idosas se sintam mais livres para realizar coisas que não poderiam antes, isto se limita a fazer aquilo que é socialmente aceito, uma vez que se sentem impossibilitadas de traçar e alcançar metas pessoais.

Como descrito por Martins (2010, p. 46) "O ser humano visto como um resultado da civilização, de seus mecanismos reguladores e padronizadores é uma contradição ao apelo interior pela liberdade restringida". É como se nesta sociedade o papel social que cabe a estes sujeitos é o de "idoso" que carrega consigo vários estereótipos e preconceitos que de(limitam) as ações e comportamentos destes indivíduos.

Quando Martins (2010, p. 46) afirma que "Os tabus estão relacionados à importância do papel que se desempenha, inclusive aos estigmas e as punições" pode-se compreender a essência da visão negativa que a velhice possui na sociedade atual. Em uma que sociedade valoriza a produtividade, a beleza e a juventude, o envelhecimento é por muitos considerado como perda destes, assim, o idoso para alguns é aquele que não produz mais e não é mais belo em virtude da velhice. Morin (2000) destaca que existe uma cultura em massa que destaca a desvalorização da velhice, e promove os valores juvenis. São inúmeros os investimentos para a contenção desse processo, para o retardamento ou controle deste envelhecimento, o que indica que o corpo velho não é desejado, mas sim, o corpo jovem (Santos \& Damico, 2009). Valença; Reis destacam que

[...] a pessoa idosa é, muitas vezes, posta à margem da sociedade, sendo associada a uma série de estigmas como o da limitação funcional, da incapacidade, da falta de papéis sociais, da improdutividade, entre outros. (2015, p. 268)

Nesta direção, se não há a atribuição de um papel social ou o exercício de um papel social relevante e almejado socialmente, não há um valor social. Faz-se necessário assim, saber diferenciar papéis sociais de identidade, para que a pessoa se posicione como protagonista na sua vida e não reprodutor de papéis controlados pela sociedade. 
Portanto, se fomentou no grupo a perspectiva de uma velhice voltada aos seus desejos pessoais, de modo que as idosas em questão possam definir de que forma querem viver e quem elas querem ser nesta fase idosa. Ressaltou-se ainda que a idade cronológica que define esta fase da vida, não necessariamente acarreta todas as características associadas a mesma e não define como elas devem viver este período. Como afirmam Schneider e Irigaray

A relação entre os aspectos cronológicos, biológicos, psicológicos e culturais é fundamental na categorização de um indivíduo como velho ou não. A pessoa mais velha, na maioria das vezes, é definida como idosa quando chega aos 60 anos, independentemente de seu estado biológico, psicológico e social. Entretanto, o conceito de idade é multidimensional e não é uma boa medida do desenvolvimento humano. A idade e o processo de envelhecimento possuem outras dimensões e significados que extrapolam as dimensões da idade cronológica (2008, p. 586).

Muitas variáveis interferem na forma como a pessoa irá experienciar a velhice, podendo esta ser vivenciada de forma positiva ou negativa, de acordo com as condições individuais de cada um (SCHNEIDER; IRIGARAY, 2008). O grupo em questão se configura como uma população idosa que se distancia do tradicional modelo de velhice propagado até então, no qual esta fase da vida é associada à um período de declínio em vários aspectos, e se associa ao modelo proposto por Silva $(2008$, p. 802) quando afirma que no cenário atual "[...] surge um modelo identitário que inclui, em sua definição, o estímulo à atividade, a aprendizagem, a flexibilidade, o aumento da satisfação pessoal e a formação de vínculos afetivos inéditos."

Diante das discussões geradas a partir do tema sobre sonhos, que expôs a repressão social que atinge as pessoas na velhice, considerou-se relevante identificar o posicionamento das idosas em relação a esta sociedade. Apesar de que, a princípio, esta relação sociedade/idoso gerou uma repercussão negativa, quando as idosas foram instigadas a falar sobre essa sociedade que lhes reprime, não se posicionaram em um papel de vítimas da mesma.

No encontro voltado a este tema, quase que em consenso as idosas relataram que esperam mais respeito e educação por parte dos jovens. Houveram muitos relatos quanto a uma juventude perdida nas drogas e com relações vazias, e o quanto isso era triste para a sociedade e principalmente para os pais. Porém, também admitiram haver certa responsabilidade dos pais nessa situação, que deveriam rever a forma como estavam educando e orientando seus filhos.

Quando indagadas quanto à possibilidade deste estilo de vida dos jovens atuais garantir a eles uma velhice igual à delas, afirmaram que não era possível, fizeram alusões a sua época, comparando as duas realidades e reforçando a necessidade de mudanças na sociedade atual. Reconheceram que não se podia generalizar a situação para todos os jovens, mas que muito menos se podia ignorar o que ocorria com frequência.

As falas demonstraram casos referentes ao desrespeito que atinge as pessoas idosas e também a indignação das mesmas frente ao panorama social contemporâneo, mas de modo geral, havia uma preocupação maior com as pessoas envolvidas nas representações negativas da sociedade (drogas, relações vazias, intimidades explicitas etc.), geralmente associadas a população jovem, do que das idosas para com elas mesmas.

Somado a isto, quando questionadas sobre o que falariam para a sociedade atual sobre a velhice sobre a necessidade desta fase da vida ser mais respeitada, de forma homogênea o grupo respondeu ser a melhor fase da vida, e quanto ao que falar, destacaram a necessidade de mudança, mas, novamente, não para um benefício próprio, de elas serem mais respeitadas ou para que os jovens de hoje sejam respeitados quando chegarem a este momento, mas sim para que eles cheguem até ele, e cheguem com a qualidade de vida que elas possuem.

As idosas em questão, demonstram vivenciar esta fase da vida, apesar das adversidades, de maneira satisfatória, o que leva ao questionamento quanto a um possível processo de resiliência no grupo, por meio do qual, se conformaram e adequaram aos padrões sociais estabelecidos, já que ao mesmo tempo que afirmam ser reprimidas pela sociedade, não se mostram de fato incomodadas com isso. 
Partindo da concepção de que a pessoa vai construir sua auto percepção a partir das experiências de aprovação ou desaprovação vividas em suas relações interpessoais, esta auto percepção vai definir como ela vai passar a se posicionar nessas relações a partir da internalização destas percepções. Silva e Marinho (2008, p. 234) defendem que "Ao sentir-se inferior, o indivíduo pode pensar que não têm nada que agrade aos outros e se coloca nos relacionamentos sem direitos [...]" podendo se submeter ou propiciar relacionamentos abusivos ou opressores.

Questiona-se ainda, diante das contradições encontradas, a possibilidade de as idosas se posicionarem como isentas das representações negativas da sociedade, ou mesmo não reconhecerem que são atingidas de alguma forma por esta, ser uma consequência de tais idosas manterem uma posição de distanciamento desta sociedade, identificado por meio de suas falas, por não se sentirem pertencentes a mesma, o que pode caracterizar uma fragilidade na sua identidade social.

Tendo o grupo em um momento oportuno, expressado sua vontade de vivenciar algo lúdico nos encontros, a partir de um resgate de histórias da infância envolvendo brincadeiras, se propiciou este momento ao mesmo, dividido em duas etapas: resgatar memórias de brincadeiras da infância, que gerou no grupo uma identificação por meio das semelhanças nas histórias contadas. Neste momento, enquanto costuravam a colcha, as idosas resgatavam suas memórias da infância, com muita empolgação, compartilhando umas com as outras as histórias de momentos envolvidas por brincadeiras. Destacaram que, na época em que eram crianças não havia e/ou não tinham condições de cumprir brinquedos, portanto tinham que dispor de muita criatividade para fazer de uma espiga de milho uma boneca, uma folha de coqueiro em um morro se tornar um escorregador. E na maioria das vezes, tinham que priorizar o trabalho à brincadeira, portanto, quando podiam de fato brincar aproveitavam o máximo o tempo que tinham.

Nos relatos como "Tínhamos que fazer nossos brinquedos, quando terminávamos, já estava na hora de parar de brincar"; "A gente fazia as letras do alfabeto em uma bacia e procurava uma lesma, a lesma ia andando na bacia e a letra onde ela parava era a letra do nome do namorado"; "Ou se não botava o nome no broto da bananeira, aquele que crescia mais era o nome do amor" as idosas foram construindo memórias de uma infância envolvida por diversas formas de brincadeira vivenciadas pelas mesmas nesta fase da vida marcada pela ludicidade.

Ressaltaram uma época de brincadeiras saudáveis e criativas, em que meninas e meninos brincavam juntos sem qualquer problema, em meio a estes resgates a colcha foi sendo construída por meio de um auxílio mútuo entre as idosas. Hora no grande grupo, hora em pequenos grupos que se formavam nesta nova configuração de encontro, histórias eram contadas e compartilhadas com carinho e sentimentos de saudade.

E, posterior a isso, a vivência de uma das brincadeiras citadas na primeira etapa, que intensificou o processo de vínculo do grupo pela necessidade maior de interação. A brincadeira foi experienciada com muita diversão, as idosas estavam animadas e de fato envolvidas com a ludicidade do encontro, passavam o anel, cuidavam para acertar o palpite sobre quem havia ficado com o mesmo e recitavam e ouviam aos versos com muita diversão. Acredita-se que juntos estes dois processos propiciaram a reafirmação da identidade social das idosas, visto que esta, segundo Moreira (2012), é constituída a partir das semelhanças encontradas no grupo.

A certa altura nos encontros percebeu-se que as idosas, além de manterem sua preocupação inicial no aspecto estético da colcha, começaram a valorizar e refletir mais sobre seu valor simbólico, querendo fazê-la da melhor maneira possível, pois esta representava suas histórias de vida. Quando se pediu que se organizassem para bater uma foto com a colcha já finalizada uma idosa propôs que a segurassem "como os jogadores seguram uma bandeira", o que foi prontamente aderido por todas. Vale ressaltar que as bandeiras se constituem como símbolos da identidade das organizações a que pertencem, e neste sentindo, frente a atitude das idosas, pode-se considerar que as mesmas internalizaram a colcha como um símbolo de identidade do grupo.

Neste processo de análise em que se reestrutura sob uma ótica teórica os encontros e respectivos temas desenvolvidos durante esta intervenção, percebe-se que as histórias compartilhadas que eram dife- 
rentes ou desconhecidas pelas demais integrantes do grupo, geravam curiosidade e interesse nas mesmas, enquanto que as histórias semelhantes ou que traziam vivências comuns entre elas, aproximavam o grupo que passava de uma atitude de narrar histórias de vida, para dialogar sobre as mesmas. Acredita-se ainda que ambos os processos influenciaram diretamente no vínculo do grupo e na identidade grupal das integrantes, ao ponto que, ao retomar o tema inicial do projeto no último encontro, ou seja, quem elas eram, a resposta do grupo se direcionou para ele mesmo, "Somos união"; "Somos este grupo!".

Quando as idosas trazem uma identidade grupal como definidora de quem elas são, percebe-se como o processo grupal é redefinidor da identidade dos seus integrantes. Procurando localizar a situação da identidade pessoal das integrantes do grupo, levou-as a refletir sobre a mesma, colocando-a como um conjunto de tudo que foi discutido durante os encontros. Isso corrobora com as afirmações de Barbosa; Reis (2009, p.4) quando diz

É importante destacar que a identidade é formada de vários papéis, e de muitas outras atividades exercidas pelo individuo, o que torna a identidade multideterminada. Esses múltiplos papéis assumem certa predominância em determinados momentos, mas todos eles se influenciam mutuamente e oferecem subsídio para a metamorfose da identidade.

Diante das exposições feitas, acredita-se terem sido alcançados os objetivos determinados, garantindo que no cenário em que eram alinhavados retalhos e momentos em uma colcha da vida, as costureiras fossem narradoras, autoras e protagonistas de suas histórias. Quando se reconhecem como um grupo, uma união, acredita-se ser uma referência ao objetivo de favorecer a identidade social a partir do reconhecimento de semelhanças e diferenças intragrupais. E, considerando que tais semelhanças e diferenças foram identificadas a partir do resgate de histórias de vida, também se propiciou o fortalecimento da identidade pessoal das idosas.

Ainda, em todos os encontros, procurou-se estruturá-los de forma acolhedora às histórias compartilhadas, fazendo jus ao objetivo de fomentar a abertura de espaços para acolhimento de expressão de sentimentos. Como ressaltam Elias e Veras (2008, p.182) "Todo ser humano precisa ter o seu momento para falar, colocar suas ideias, expressar suas opiniões e sentimentos.", para Mesquita e Carvalho (2014, p. 1128) "[...] a escuta apresenta-se como uma estratégia de comunicação essencial para a compreensão do outro, pois é uma atitude positiva de calor, interesse e respeito, sendo assim terapêutica.".

Entende-se a escuta, assim, complementar a fala, não podendo ter-se resultados positivos se acontecerem separadamente. Sendo assim, acolheu-se e incentivou-se o grupo a acolher as histórias compartilhadas e os sentimentos relativos as mesmas, inclusive a confecção dos fuxicos teve por objetivo garantir que o grupo mantivesse sua atenção nos relatos e que a pessoa que havia contado sua história e recebesse um fuxico ao final do encontro se sentisse ouvida e acolhida. Tornando cada história essencial para a reafirmação do grupo e seus integrantes, assim como cada retalho era fundamental para a confecção da colcha.

\section{CONSIDERAÇÕES FINAIS}

Constatou-se por meio das esferas teóricas e práticas desta intervenção, que a identidade é uma temática de grande relevância na velhice, e que os conhecimentos e a atuação da psicologia podem contribuir positivamente neste processo. Nesse sentido, sugere-se novas intervenções e pesquisas neste contexto que contemplem o sentido identitário dos idosos, principalmente diante da intergeracionalidade.

Sugere-se também a continuidade deste projeto e sua aplicação em demais contextos, reconhecendo na colcha de retalhos um potente objeto intermediário para ampliação de pertenças e reintegração de histórias pessoais. 


\section{REFERÊNCIAS}

BARBOSA, I. G.; REIS, Fernando Figueredo dos Santos . O papel da família na constituição da identidade na infância: a perspectiva veiculada em livros e periódicos de psicologia e a visão sócio-cultural dos vygotskyanos. 2009. In: 63a Reunião Anual da SBPC Cerrado: Água, Alimento e Energia. Anais... Goiânia - GO: UFG - Universidade Federal de Goiás - Campus Samambaia, 2011. p. 10. Disponível em: < https://eventos.fe.ufg.br/up/248/o/1.5._2_.pdf>. Acesso em: 09 jun. 2018.

BERLATTO, Odir. A construção da identidade social. Revista do Curso de Direito da FSG Caxias do Sul, ano 3 n. p. 141-151, 5 jan./jun. 2009. Disponível em: $<$ http://ojs.fsg.br/index.php/direito/article/viewFile/242/210>. Acesso em: 22 abr. 2018.

CUBA, Conceição De Maria Goulart Braga. Ninguém Vive sem Amizade: A Importância da Amizade Política dos Idosos Colaboradores da UNATI/UERJ. 2006. 261 f. Tese (Mestre em serviço social) - Pontifícia Universidade Católica do Rio De Janeiro. Rio de Janeiro. Disponível em: https://www.maxwell.vrac.puc-rio.br/Busca_etds.php?strSecao=resultado\&nrSeq=8564@1. Acesso em: 09 jun. 2018.

ELIAS, Gizele G. Parreira; VERAS, Mariana Oliveira. Psicologia Escolar: Abrindo Espaço para a Fala, a Escuta e o Desenvolvimento Interpessoal. Revista da Abordagem Gestáltica - XIV(2): 182-189, jul-dez, 2008. Disponível em: < http://pepsic.bvsalud.org/pdf/rag/v14n2/v14n2a05.pdf>. Acesso em: 15 jun. 2018.

FERREIRA, Teresa Helena Schoen; FARIAS, Maria Aznar; SILVARES, Edwiges Ferreira de Mattos. A construção da identidade em adolescentes: um estudo exploratório. Estudos de Psicologia, 8(1), p. 107-115, 2003. Disponível em: < http://www.scielo.br/pdf/epsic/v8n1/17240>. Acesso em: 22 abr. 2018.

GIL, Antonio Carlos. Métodos e técnicas de pesquisa social. 6. ed. - São Paulo: Atlas, 2008.

MARTINS, Eduardo Simões. Os papéis sociais na formação do cenário social e da identidade. Kínesis, Vol. II, nº 04, p. 40-52, dez. 2010. Disponível em: < http://www.marilia.unesp.br/Home/RevistasEletronicas/Kinesis/Ospapeissociaisnaformacao.pdf $>$. Acesso em: 09 jun. 2018.

MARTINS, Karina Donizete; SANTOS, Eldivan Ferreira dos; CAROLINO, Luciania Nunes. Integração social da pessoa idosa: políticas públicas relacionadas e atuação do CRAS de Redenção - PA na inserção do idoso em programas de proteção social. Revista Libertas, v. 15, n. 1, p. jan./ jul. 2015. Disponível em: <https://periodicos.ufjf.br/index.php/libertas/ article/view/18316 >. Acesso em: 21 abr. 2018.

MEIRA, S. S. et al. Idosos em estado de corresidência em um município do interior da Bahia. O Mundo da Saúde, São Paulo, 2015, 39 (2), p. 201-209. Disponível em: < http://www.saocamilo-sp.br/pdf/mundo_saude/155570/A08.pdf>. Acesso em: 21 jun. 2018.

MESQUITA, Ana Cláudia; CARVALHO, Emilia Campos de. A Escuta Terapêutica como estratégia de intervenção em saúde: uma revisão integrativa. Rev Esc Enferm, USP, 2014; 48 (6), pp.1127-36. Disponível em: < http://www.scielo.br/ pdf/reeusp/v48n6/pt_0080-6234-reeusp-48-06-1127.pdf>. Acesso em: 15 jun. 2018.

MIRANDA, Luciene Corrêa; BANHATO, Eliane Ferreira Carvalho. Qualidade de vida na terceira idade: a influência da participação em grupos. Psicol. pesq.[online]. 2008, vol.2, n.1, p. 69-80. ISSN 1982-1247. Disponível em: <http://pepsic. bvsalud.org/pdf/psipesq/v2n1/v2n1a09.pdf>. Acesso em: 09 jun. 2018.

MOREIRA, Aline Hack. A identidade social do idoso e as relações de trabalho: a realidade por trás das salvaguardas legais. Revista Kairós Gerontologia, São Paulo, 15(2), p. 91-107, mar. 2012. Disponível em: <https://revistas.pucsp.br/ index.php/kairos/article/view/13108/9637>. Acesso em: 21 abr. 2018.

MORIN E. Cultura de massas no século XX. Rio de Janeiro: Forense Universitário; 2000. v.1.

OLIVEIRA, João Batista Alves de; LOPES, Ruth Gelehrter da Costa. O processo de luto no idoso pela morte de cônjuge e filho. Psicologia em Estudo, Maringá, v. 13, n. 2, p. 217-221, abr./jun. 2008. Disponível em: < http://www.scielo.br/ pdf/pe/v13n2/a03v13n2 >. Acesso em: 09 jun. 2018. 
OMS, Organização Mundial da Saúde. (2015). Relatório mundial de envelhecimento e saúde: Resumo. Disponível em: http:// apps.who.int/iris/bitstream/handle/10665/186468/WHO_FWC_ALC_15.01_por.pdf?sequence=6. Acesso em: 18 mar. 2018.

PAPALIA, Diane E; FELDMAN, Ruth Duskin. Desenvolvimento Humano. 12 Ed. Porto Alegre: Artmed, 2013. 800p.

PAÚL, Constança. Envelhecimento activo e redes de suporte de social. Sociologia, Revista da Faculdade de Letras da Universidade do Porto. v. 15, 2005. p. 275-287. Disponível em: <http://ojs.letras.up.pt/index.php/Sociologia/article/ view/2392/2189>. Acesso em: 20 jun. 2018.

SANTOS, M. F. S. Identidade e aposentadoria. São Paulo: EPU, 1990.

SANTOS, Maria de Fátima de Souza. Velhice: uma questão psico-social. Temas psicol, Ribeirão Preto, vol.2, n.2, p. 123131. ago. 1994. Disponível em: <http://pepsic.bvsalud.org/pdf/tp/v2n2/v2n2a13.pdf>. Acesso em: 22 abr. 2018.

SANTOS, Flávia da Cruz; DAMICO, José Geraldo Soares. O mal-estar na velhice como construção social. Pensar a Prática, v. 12, n. 1, 2009. Disponível em: <https://www.revistas.ufg.br/fef/article/view/4439> Acesso em: 2 mar. 2020.

SCHNEIDER, Rodolfo Herberto; IRIGARAY, Tatiana Quarti. O envelhecimento na atualidade: aspectos cronológicos, biológicos, psicológicos e sociais. Estudos de Psicologia, Campinas, 25(4), p. 585-593, out./dez. 2008. Disponível em: $<$ http://www.scielo.br/pdf/estpsi/v25n4/a13v25n4.pdf >. Acesso em: 15 jun. 2018.

DA SILVA, Antônio Isidro; MARINHO, Geison Isidro. Auto-estima e relações afetivas. Universitas: Ciências da Saúde, v. 1, n. 2, p. 229-237, 2008. Disponível em: <https://www.arqcom.uniceub.br/cienciasaude/article/view/507>. Acesso em: 15 jun. 2018.

SILVA, Luna Rodrigues Freitas. Terceira idade: nova identidade, reinvenção da velhice ou experiência geracional? Physis - Revista de Saúde Coletiva, Rio de Janeiro, vol. 18, núm. 4, out./dez. 2008, p. 801-815. Disponível em: < http://docplayer. com.br/11456297-Physis-revista-de-saude-coletiva-issn-0103-7331-publicacoes-ims-uerj-br-universidade-do-estado-do-rio-de-janeiro-brasil.html>. Acesso em: 15 jun. 2018.

VALENÇA, T.D.C.. REIS, L.A.dos.. Memória e história de vida: dando voz às pessoas idosas. Revista Kairós Gerontologia, São Paulo, 18 (2), p. 265-281, abril-junho. 2015. Disponível em: < https://revistas.pucsp.br/index.php/kairos/ article/view/27001/19143>. Acesso em: 21 abr. 2018.

\begin{tabular}{|c|c|}
\hline Histórico & $\begin{array}{l}\text { Recebido em: 04/06/2016 } \\
\text { Revisado em: 18/06/2017 } \\
\text { Aceito em: 09/05/2019 }\end{array}$ \\
\hline Contribuição & $\begin{array}{l}\text { Concepção: HCH; AC. } \\
\text { Coleta de dados: HCH; AC } \\
\text { Análise de dados: HCH; GPV; AC } \\
\text { Elaboração do manuscrito: HCH; GPV; AC } \\
\text { Crítico revisões de conteúdo intelectual importante: AC } \\
\text { Aprovação final do manuscrito: HCH; GPV; AC }\end{array}$ \\
\hline Financiamento & Não houve financiamento. \\
\hline $\begin{array}{l}\text { Aprovação, ética e } \\
\text { consentimento }\end{array}$ & O estudo foi aprovado pelo comitê de ética em pesquisa através do parecer 2.970.336. \\
\hline
\end{tabular}

